\title{
Outreach and Engagement: Evolving Media and the Public Obligations of Stem Cell Science
}

\author{
Alan C. Regenberg ${ }^{1}$ - Theodore E. Schall ${ }^{1}$
}

Published online: 5 September 2015

(C) Springer International Publishing AG 2015

\begin{abstract}
Outreach and engagement occupy ends of a spectrum as forms of public participation. Most scientists agree that outreach and engagement are important, and most participate at least occasionally. A wide array of tools can and should be utilized for effective outreach and engagement. Risks and challenges are present and manageable. Along with other scientists, stem cell scientists and their institutions have an obligation to ensure that their work proceeds in parallel with robust outreach and engagement efforts. Social mediabased tools can be valuable for discharging these duties.
\end{abstract}

Keywords Stem cell $\cdot$ Science $\cdot$ Engagement $\cdot$ Outreach · Communication $\cdot$ Social media $\cdot$ Apomediation

\section{Introduction}

Outreach and engagement are necessary for science to proceed with transparency and public trust. Stem cell science has attributes that highlight both the necessity and challenges associated with outreach and engagement. Stem cell science is not always easy to discuss. The science is complex and quickly evolving. Its physical scale makes it inaccessible to non-scientists, many of whom struggle to grasp its basic tenets. The

This article is part of the Topical Collection on Ethics in Stem/Progenitor Cell Therapeutics

Alan C. Regenberg

alanr@jhu.edu

Theodore E. Schall

theoschall@jhu.edu

1 Johns Hopkins Berman Institute of Bioethics, 1809 Ashland Avenue, Baltimore, MD 21205, USA field is controversial and has been at the center of vigorous political, theological, and ethical debates. Scientifically unfounded treatments have been hyped as miracle cures. Many of these attributes are not unique to stem cell science and can be found in other fields of science.

Around the United States and the world, political reactions to stem cell science have resulted in a patchwork quilt of legislative responses including criminalization, legalization with state funding, and jurisdictions with no particular oversight (e.g., see http://www.hinxtongroup.org/wp.html) [1]. These disparate policies reflect a lack of consensus on and understanding of the methodologies, potential, and value of stem cell science.

Human embryonic stem cells (hESCs) remain particularly controversial $[2,3]$. Significantly, the use of these embryoderived cells requires the destruction of human embryos, which raises questions about the moral status of the embryo. For those who believe that life begins at conception, particularly those with views rooted in religious traditions, this destruction can be seen as tantamount to murder. Such positions can be especially challenging to engage in dialogue due to incommensurability of religious and secular approaches [4]. Other objections have been raised over the potential for some methods in stem cell research to lead to an inevitable fall down the slippery slope to morally objectionable human cloning [5].

Even for proponents, stem cell science's value remains largely theoretical. The oft-cited promise of stem cellbased interventions has yet to produce a real therapeutic blockbuster. The nature of the currently untreatable diseases that have been proposed as targets for early translation has led to an environment where patients' hopes are sometimes inflated by hype [6•].

Similar attributes to those detailed above will be found in other areas of science where international research involves cutting edge technology and promising translation (e.g., gene 
therapy, deep brain stimulation, assisted reproductive technologies, etc.). While specific details may vary, the broader challenges that make outreach and engagement essential are fairly consistent for stem cell science and for other areas in science. Ultimately, there is deep interest in understanding the work of science and developing consensus around its wisdom and value.

\section{What Do We Know About Science Outreach and Engagement?}

\section{Outreach/Engagement is Essential}

The language we use to describe activities that encourage encounters with science tells us a great deal about our goals and commitments. For the purposes of this review, we will simplify and conceptualize activities as along a spectrum ranging from pure outreach to engagement [7]. The difference between outreach and engagement lies in the relationship between scientific authorities (scientists and their institutions) and the public. Outreach is focused on actions taken by scientific authorities to disseminate information in an effort to educate and inform. Examples of outreach include publications (in academic and lay press), responding to media inquiries, and public lectures and events.

Engagement focuses on encounters between scientific authorities and non-expert groups. Engagement activities encourage two-way discussions. Engagement can include both less formal discussions and carefully constructed deliberative engagement events intended to answer research questions [8•]. Engagement can present novel challenges, e.g., scientific authorities have less control over the agenda in two-way discussions and it is not always clear what to do with the information that is learned in these encounters.

For this review, we are limiting our focus to adults. Children's encounters with science are obviously important, but there is a sufficient difference in the capacities, roles, and responsibilities of children versus adults to warrant setting children's encounters aside for separate consideration, perhaps in collaboration with professional educators.

Polling suggests that virtually all (as high as $98 \%$ ) scientists participate in some form of outreach or engagement, at

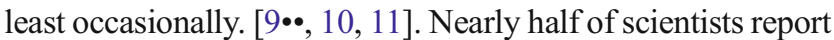
using social media to discuss or follow science [9••]. Participation is not evenly distributed. Older, more senior scientists are more likely to report speaking with journalists. Those with previous communication training or positions that include teaching responsibilities are also more likely to report outreach and engagement activities. [10]. Social media use skews towards younger scientists, but actual blogging is evenly distributed among those under $65[9 \bullet \bullet]$.
There is broad and deepening consensus that some forms of outreach and/or engagement are essential for science $[9 \bullet \bullet, 10$, $12,13]$. A consistent majority has voiced support for the active participation of scientists and their institutions in at least some of what has been described as "the full range of ways in which adults encounter the ideas, people, processes, stories, and objects of science" [13]. While there is general agreement that some sort of outreach or engagement is important, there is less agreement about the specifics of how and why this should happen. Questions abound. What type of outreach and engagement? How much is required? With whom? If efforts are directed at the public broadly, some careful thought needs to be given to ensuring adequate representativeness [14]. Likewise, if efforts focus on key stakeholder groups, this requires the key stakeholders to be identified in some uncontroversial manner.

There appears to be a general trend over time of moving from outreach to engagement. The trend is likely motivated by critiques of outreach being used merely as a not fully legitimate tool for gaining public acceptance through eliminating knowledge deficits, rather than as a truly participatory process $[14,15]$. However, the conceptualization of outreach and engagement as the endpoints of a spectrum is meant to serve as a reminder that activities often include elements of both. It ought to be possible to heed the cautions about the shortcomings of outreach while recognizing that science can be complex and rapidly changing, requiring some outreach to help facilitate efficient and effective participatory discussions about the implications of this science.

\section{Many Ways to Encounter Science}

The full range of potentially valuable outreach and engagement activities is vast. Adults can encounter the ideas, people, processes, stories, and objects of science in a staggering variety of ways. Examples include museum exhibits, live events, MOOCs, blogs, vlogs, comments, twitter chats, poetry, drama, literature, documentary film, and more. While this full range of media is available to many scientists, a scientist's selection from the menu of options typically is shaped by multiple contextual factors, including budget, primary audience/participants, and goals.

A traditional strategy for outreach involves interactions with mass media, typically with scientists working with journalists to communicate about scientific research $[6 \bullet, 9 \bullet \bullet, 16]$. When stars align, media engagement can offer the benefit of providing a platform for scientists to discuss their work at the very time that there is broader public interest in the story [16]. Multi-directional dialogue can be fostered between scientists and the public, with members of the media helping to clarify and amplify salient points. 


\section{From Traditional to Social Media}

Recent rapid changes to communication technologies have helped to facilitate the shift towards engagement. In the past, partnerships with traditional broadcast media outlets were essential for disseminating information about science. Over the past few decades, we have witnessed the rapid expansion of social media [17]. Social media can be distinguished from traditional broadcast media by how information is easily shared, recommended, filtered, and commented upon by users. Traditional media, in contrast, is typically broadcast from one source to a large audience. Traditional media remains important, but it is increasingly just one among many paths for sharing information broadly.

Distinctions between traditional and social media are becoming less useful as traditional media is increasingly also posted as social media. For example, NPR will produce a stem cell science news segment for radio broadcast. This story will also be posted on their blogs in text format with the audio embedded. Here, it can receive comments and be shared through popular social media platforms such as Twitter and Facebook. The public responds to the news of a new scientific breakthrough on a platform shared by scientists, allowing for an equal-access discussion between experts and non-experts.

The increasing prevalence of social media, which is collaborative in nature, may be helping to shift scientists' interactions with the public from outreach towards more interactive engagement efforts $[18,19,20 \bullet \cdot$.

\section{Why Engage?}

The need for science outreach and engagement is frequently voiced in terms of scientific authorities' obligations or duties, sometimes rooted in public accountability or democratic legitimacy $[14,16,21,22]$.

Some subscribe to a narrowed version of this duty to argue that recipients of state funds have a simpler obligation, rooted in the idea of accountability, to make efforts to explain their work to the taxpayers who make this funding possible [22]. This claim could be modified to describe obligations based on accountability to include private funders and still require some level of outreach and engagement.

Other claims suggest that broad segments of society have important stakes in the work and the translated products of science and scientific research. Stakeholders ought to have access to and input in this work that directly impacts them. Scientists must engage with others for this to happen [14].

Scientists may also be obligated to enhance public trust by ensuring adequate transparency about their work through outreach and engagement activities [22, 23]. The rationale here can either be based on enhanced trust as a good in itself or as a necessary part of a societal "contract" that grants scientists certain privileges while creating obligations, including maintaining public trust in their work.

Another argument focuses on the value of facts and truth. Scientists, as experts, have an obligation to share their knowledge so as to correct misperceptions, particularly misperceptions that appear common [20••]. In the case of stem cell research, scientists might arguably have an obligation to publicly temper any hype associated with the publication of scientific papers and also explain what kinds of treatments have been scientifically validated to help correct misunderstanding resulting from the rhetoric of "miracle cures."

It has also been argued that there are substantive reasons to pursue engagement, as engagement can ensure the inclusion of multiple, diverse perspectives and result in better, more robust, more socially acceptable, and rapidly adopted outcomes than science left up to sponsors and scientists alone [14].

Most scientists support the notion that outreach and engagement are necessary, with nearly nine out of ten voicing support for the statement that scientists should be involved in public policy debates involving science and technology [9••]. Most scientists also report a belief that non-expert groups hold an interest in their work and its importance [24•]. Interestingly, scientists who report more debate about their work in the media are more likely to voice an opinion that engaging via mass media and social media are important for their career $[9 \cdot \bullet]$.

\section{Goals and Benefits}

Some scientists express more pragmatic and self-interested goals and anticipated benefits for outreach and engagement. Often, these can lean more towards the outreach end of the spectrum. Examples include explaining complex science and its importance to the non-expert public, funders, and policy makers; burnishing the profile of science, scientists, and their institutions in order to influence continued funding and supportive policy; and to aid in attracting the next generation of bright new scientists $[9 \bullet \bullet, 10,22]$.

This focus on outreach as a preferred mode of public engagement is supported by the results of polling of scientists themselves. Asked to define what engaging with the nonspecialist public meant to them, scientists offered as the most common response: to explain and promote public understanding of science (34\%). This was followed by highlighting the implications, relevance, and value of science $(15 \%)$ and giving a public lecture (13\%) [10]. These results are fairly consistent with other findings [11], which support scientists' preference for outreach.

Work at the engagement end of the spectrum, while not the most common response, was, at least, among the most common responses. Still on the list, but least common among responses was listening to and understanding the public 
(13\%) [10]. Increasing awareness of the importance of engagement is also evidenced by the emergence of some major initiatives and programs [25-27].

We can see the value of public engagement, in action. The UK launched a stem cell public engagement consortium, the Stem Cells Dialogue, in 2007. The two primary aims of this project were to "engage the public about developments in stem cell research, in order that their views can be taken into account in policy development by Research Councils, the scientific community and policy makers; and to contribute to creating an environment across sectors and groups that will sustain dialogue on issues relating to developments in stem cell research and their clinical applications" [25].

More recently, the UK completed another public dialogue around the complex and controversial science of mitochondrial donation techniques as a means of addressing mitochondrial disease [26]. Following this engagement, the UK parliament passed legislation to allow their Human Fertilisation and Embryology Authority to review proposals and potentially license the use of this technology.

Looking forward, public engagement is included as a prominent feature of the Horizon 2020 framework for EU research and innovation funding. It is expected to play a significant role in the funding supporting research with better, more rapid, and more acceptable outcomes [27].

While these examples represent significant investments in engagement, careful research will be required to measure the impact of these engagements over time to ascertain the extent to which engagement efforts have achieved their goals and other effects they may have had on both scientists and the public.

\section{Fears and Risks}

While support for and participation in outreach and engagement may be increasing, there is also some evidence suggesting that outreach and engagement activities, while important, represent the start of a process rather than any quick solution in themselves. A commitment to outreach and engagement as part of science will require many challenges to be confronted over time and through sustained efforts with varying results.

Scientists and scientific institutions can be hesitant to communicate with the public. A litany of fears has been raised about outreach and engagement via traditional media. These include worries about the quality of reporting possible in the context of a hungry 24-h news machine [16]. Concerns have also arisen over misquotes, unskilled reporting that elevates unworthy science and bad arguments, and suggestions of false equivalence between differing views. Yet, there are also risks that come with not participating in public debates. Sitting out debates risks leaving bad arguments unanswered by expert voices [28]. For example, media coverage of athletes' and other celebrities' use of unproven stem cell-based interventions rarely $(27 \%)$ included any mention of whether there was evidence that these interventions were efficacious [29], let alone expert analysis of the current state of evidence regarding stem cell science translation.

Apart from fretting over the risks and challenges of participating with the media and in public debates, scientists commonly report concerns about institutional support for their time spent in outreach and engagement (including financial support for these activities and receipt of appropriate credit on evaluation). Scientists also express worries over inadequate training and experience [12]. Calls for increased outreach and engagement arrive in the context of reduced funding and increasing commitments in the day-to-day working lives of many scientists [30]. Additionally, scientists see a barrier in their perception that the public and the media lack knowledge and interest in science (while believing that the public holds their work in high esteem) $[9 \bullet \bullet, 12]$.

Polling reveals significant gaps in views of science held by scientists and the public. Notably, recent polling finds greater than $10 \%$ differences in support for statements about a range of hot-button issues including vaccination, evolution, and climate change $[12,24 \bullet]$. While scientists feel they are viewed favorably by the public, actual public responses are significantly less (though still) favorable. A survey comparing scientist and non-specialist public views of the attributes of scientists shows gaps of more than $20 \%$ in responses for 13 of 27 of the attributes [12]. Relationships between scientists and the lay public may be complicated, particularly in the USA, by the interplay of science with religious perspectives [31].

A different sort of challenge that complicates the relationship between science and the public is hype. This challenge was raised in a recent content analysis of press coverage of translational stem cell research which identified highly optimistic timelines as a consistent problem. The authors found scientists playing a causal role by providing authoritative statements that could spur unrealistic expectations [5]. Unwarranted optimism in media coverage, with less focus on the particular obligations of scientists, has been identified as a challenge in other areas of science as well [32]. An examination of the portrayal of translational stem cell research in daily newspapers in the USA, UK, and Canada found consistent evidence of highly optimistic, unrealistic timelines [33].

Along similar lines, we know that there are providers offering a wide range of stem cell-based interventions ahead of sufficient evidence on safety and efficacy [34-36]. While the extent of engagement between these providers and the public is hard to measure, the ample presence of online evidence suggests that efforts to reach potential cell-based intervention recipients in this manner have been effective [37]. Many scientists are rightly concerned about the potential impact of these untested interventions [38, 39]. Patients could be harmed financially, mentally, and physically. Bad outcomes 
could have a chilling effect on legitimate stem cell research elsewhere.

One institutional response to this challenge has come from the International Society for Stem Cell Research (ISSCR). The ISSCR has undertaken an outreach effort by creating a website aimed at educating the general public about untested stem cell-based interventions, including how to evaluate them and their implications [40]. The hope is that potential patients will find guidance on evaluating untested stem cell therapies just as easily as they find advertisements for those therapies. As a means to counter this problem, some have argued for responses that focus more on engagement with patients, recognizing the role of desperation and hope in influencing tough choices [41]. There have also been arguments for the creation of new engagement-focused roles for experts to serve as stem cell counselors, akin to genetic counselors [42•].

A different take on the problem of hype and its origins focuses on the segment of non-expert society, akin to a subculture, for whom enthusiasm for science is a social signifier. As "geek" culture has made its way into the mainstream, a shallow "love" of science has gained cachet. This coincides with rise in prominence of social media use, particularly its use in sharing recommendations, often devoid of further explanation. A popular blog post on the subject coined the new term "scienceyness" (borrowing from Stephen Colbert's "truthiness") and reflected on the hazards of "sciencey" headlines. These are "pre-packaged cultural tokens that can be shared and reshared without any investment in analysis or critical thought...to reinforce one's aesthetic selfidentification as a 'science lover." Scienceyness and misguided science fandom, it is argued, result in uncritical hyping and farther raise unrealistic expectations [43].

Taken with a recent analysis that reported high levels of satisfaction among scientists in their experiences with media contacts [11], the cultural drive towards scienceyness suggests a risk that media contacts might provide an uncritical sounding board for scientists to promote views without sufficient expectation that their claims will meet with any thoughtful pushback.

Turning to focus specifically on social media, we find yet more unique fears and risks. These include concerns about quality, a lack of control over content (including comments pulled out of context and shared widely), and, of course, the infamous trolls lying in wait to ambush the unwary with their inflammatory remarks.

\section{Conclusions}

\section{What is the Proper Role for Scientists in Civic Life?}

Scientists, in general, and stem cell scientists, in particular, have an obligation to ensure that their work proceeds in parallel with robust outreach and engagement efforts. The arguments in support of this are varied and compelling. Scientists should be accountable; their work is best undertaken transparently; they should strive towards democratic legitimacy through public debates over the risks and merits of their work. Scientists are given license to experiment and are obligated to engage with the public about their plans and findings. Robust outreach and engagement ought to yield both better science and better, more widely adopted outcomes.

This is a professional obligation and not necessarily an individual obligation. It is possible to be a good scientist and valuable member of the scientific community without being a good public communicator and without being personally active in outreach and engagement efforts. Institutions must ensure that they have someone to serve as a good representative who can participate in outreach and engagement around all of the work occurring at that institution.

While not all scientists can be effective as participants in outreach and engagement, exceptions should be made only for good reasons. Scientific institutions should make every effort to provide support to ensure that as many scientists as possible can fully participate in outreach and engagement. In order to ensure success, institutions must recognize the importance of training/mentoring, particularly for students and early career scholars. This should include traditional and social media training-most likely in collaboration with outside experts, and integrated into the larger educational program.

Institutions should encourage and support mentors to provide formal and informal training. Likewise, institutions should provide infrastructure and support to make engagement more effective. This can include hiring relevant experts and establishing routinely facilitated channels for outreach and engagement.

Outreach and engagement activities should be well funded and valued. In other words, these activities should count towards promotion similarly to other scholarly activities. Scientists' best efforts will be profoundly stymied without this essential support. Ultimately, this will require additional work towards identifying and refining appropriate metrics for evaluating impact and success across a wide range of possible activities, but less than ideal metrics are not sufficient to serve as an excuse to avoid obligations.

This paper focuses on the responsibilities of scientists and their institutions. Responsibilities for ensuring successful outreach and engagement also extend to a range of other parties such as members of the public, interest groups, and funders. Government entities in particular should support effective public dialogue.

While extolling the value of outreach and engagement, it is important to recognize that risks and challenges will endure. Strategies to address known risks and challenges should be built into efforts. Research should be conducted to identify unknown risks and challenges. Refined strategies for effective 
outreach and engagement should consistently be developed, refined, and deployed. Best practices are likely to evolve over time and will require vigilant monitoring.

\section{Social Media to the Rescue}

Broad access to the internet [17] and the rise of social media may be helping to nudge activities from outreach towards engagement [44]. In the past, access limitations reified the importance of expert intermediaries (scientists) in controlling access to scientific knowledge and wisdom. Social media platforms support a shift away from the need for expert intermediaries by making possible an apomediated environment, in which users can help each other to access and understand complex science. This concept was initially introduced in the context of medicine but can also been applied to provide more widespread access to science $[18,19,20 \bullet \bullet]$. With effort, scientists can move from being expert intermediaries and participate alongside fellow experts and non-experts alike as apomediators.

In addition to facilitating conceptual shifts from intermediated to apomediated engagement, social media offers an important opportunity for stem cell science engagement. As mentioned above, all media are (potentially) social media. The increasingly fuzzy line between traditional media and social media blurs former distinctions and increases the options available for engagement.

Social media offers a tool that is custom designed for engagement. It has other attractive attributes: it is global, inexpensive, easy to use, and it provides a level playing field. Engagement via social media can happen in real time, or it can be a platform for sustained interactions where users can respond at their convenience and carry on discussions over time.

Controversial topics, like stem cell science, tend to draw heat via social media. This can be both a pro and a con. If recognized and managed, the capacity to draw attention should predominantly be a benefit, as it enhances opportunities for virality and cutting through the noise of a broadly decentralized world.

The power and convenience of social media comes with additional risks, but they should be manageable. While there is a growing list of individuals who have had their lives altered and careers destroyed through illconsidered social media contributions [45], these individuals have, by and large, been the means of their own downfall. Social media platforms merely create a new public square, with some unique features. The basic skills required for successfully navigating life in public, such as mindfulness about how one comports oneself and a commitment to civility, are the same skills needed for success with social media. In other words, we have always had people who have courted trouble by behaving badly in public. Training can help clarify features and limits, but social media essentially requires importing old skills into a new arena.

Scientists and their institutions are obligated to ensure that there is robust participation in outreach and engagement, and social media-based tools ought to be included among the resources accessed in order to discharge these duties.

Outreach and engagement are different and important types of public participation. Outreach and engagement can helpfully be envisioned along a spectrum ranging from broadcasting out information to actively participating in conversations. Most scientists agree that these activities are important, and almost all participate in some form of these activities, if only occasionally. Along with other scientists, stem cell scientists and their institutions have an obligation to ensure that work in their particular areas proceeds in parallel with robust outreach and engagement efforts. There are many paths towards effective outreach and engagement. Social media-based tools can be particularly valuable for discharging these duties. Risks and challenges associated with outreach and engagement activities are present and manageable.

\section{Compliance with Ethics Guidelines}

Conflict of Interest Alan Regenberg and Theo Schall declare that they have no conflict of interest.

Human and Animal Rights and Informed Consent This article does not contain any studies with human or animal subjects performed by any of the authors.

\section{References}

Papers of particular interest, published recently, have been highlighted as:

- Of importance

• Of major importance

1. Mathews DJH, Donovan P, Harris J, et al. Integrity in international stem cell research collaborations. Science. 2006;313:921-2.

2. King NMP, Perrin J. Ethical issues in stem cell research and therapy. Stem Cell Res Ther. 2014;5:85.

3. Holm S. Going to the roots of the stem cell controversy. Bioethics. 2002;16:493-507.

4. Stempsey WE. Religion and bioethics: can we talk? Bioeth Inq. 2011;8:339-50.

5. Hyun I. Policy: regulate embryos made for research. Nature. 2014;509:27-8.

6. Kamenova K, Caulfield T. Stem cell hype: media portrayal of therapy translation. Sci Transl Med. 2015;7:278ps4. The authors 
present results from a content analysis of major daily news reports describing portrayals of stem cell research.

7. International Association for Public Participation (IAP2). Public participation spectrum. 2015. Available from: https://www.iap2. org.au/resources/iap2s-public-participation-spectrum

8. Daugherty EL, Gwon H, Schoch-Spana M, et al. The community speaks: understanding ethical values in allocation of scarce lifesaving resources during disasters. Ann Am Thorac Soc. 2014;11:77783. The authors describe results from a pilot project designed to adapt deliberative democratic procedures to engage with community members.

9.• Pew Research Center. How scientists engage the public [Internet]. Pew Research Center. 2015. [cited 2015 April 15]. Available from: http://www.pewinternet.org/2015/02/15/how-scientists-engagepublic/. This report presents results from a recent and comprehensive survey of 3,748 scientists connected with the American Association for the Advancement of Science detailing how and why they engage with the public.

10. The Royal Society. Science communication: survey of factors affecting science communication by scientists and engineers [Internet]. The Royal Society. 2006. [cited 2015 April 15]. Available from: https://royalsociety.org/ /media/Royal_Society_ Content/policy/publications/2006/1111111395.pdf

11. Peters HP, Brossard D, de Cheveigné S, et al. Interactions with mass media. Science. 2008;321:204-5.

12. Market \& Opinion Research International (MORI). The role of scientists in public debate [Internet]. The Wellcome Trust. 2000. [cited 2015 April 15]. Available from: http://www.wellcome.ac. uk/stellent/groups/corporatesite/@msh_peda/documents/web_ document/wtd003425.pdf

13. Massachusetts Institute of Technology, Culture Kettle. The evolving culture of science engagement: an exploratory initiative of MIT \& Culture Kettle [Internet]. MIT \& Culture Kettle. 2014. [cited 2015 April 15]. Available from: http://www. cultureofscienceengagement.net/s/Evolving-Culture-of-ScienceEngagement-Phase-1-Report.pdf

14. Mohr A, Raman S. Representing the public in public engagement: the case of the 2008 UK stem cell dialogue. PLoS Biol. 2012;10: e1001418.

15. Mander J. Digital vs traditional media consumption summary [Internet]. GlobalWebIndex. 2014. [Cited 2015 April 15]. Available from: http://insight.globalwebindex.net/hs-fs/hub/ $304927 /$ file-1414878665-pdf/Reports/GWI_Media_ Consumption Summary Q3 2014.pdf

16. Fox F. Engaging with the media. Lancet. 2014;383:S6-7.

17. Pew Internet Project. Social networking fact sheet. 2015. Available from: http://www.pewinternet.org/fact-sheets/social-networkingfact-sheet/

18. Eysenbach G. Medicine 2.0: social networking, collaboration, apomediation, and openness. JMIR. 2008;10:e22.

19. O'Connor D. Apomediation and the significance of online social networking. AJOB. 2009;9:6-7.

$20 . \bullet$ O'Connor D. Apomediation and ancillary care: researchers' responsibilities in health-related online communities. IJIRE. 2010;3:87103. The author argues that health-related online communities are online environments in which information is apomediated. Scientists investigating such communities have a responsibility to become apomediaries themselves to help mitigate the harm of misinformation.

21. Scheufele DA. Science communication as political communication. PNAS. 2014;111:13585-92.

22. Heagerty B. Dissemination does not equal public engagement. J Neurosci. 2015;35:4483-6.

23. Lachapelle E, Montpetit É, Gauvin J-P. Public perceptions of expert credibility on policy issues: the role of expert framing and political worldviews. Policy Stud J. 2014;42:674-97.
24. Pew Research Center. Public and scientists' views on science and society [Internet]. Pew Research Center. 2015. [cited 2015 April 15]. Available from: http://www.pewinternet.org/files/2015/01/PI ScienceandSociety_Report_012915.pdf This recent report details survey results detailing how scientists and the public view science-related issues.

25. Medical Research Council, Biotechnology \& Biological Sciences Research Council, Sciencewise, et al. Stem cell dialogue [Internet]. 2008. [cited 2015 April 15]. Available from http://www.bbsrc.ac. uk/documents/stem-cell-final-report-pdf/

26. Darby H. Mitochondria replacement consultation: advice to Government [Internet]. Human fertilisation and embryology authority. 2013. [Cited 2015 April 15]. Available from : http://www. bbsrc.ac.uk/documents/stem-cell-final-report-pdf/

27. European Commission. Horizon 2020: the EU framework programme for research and innovation. Public engagement in responsible research and innovation [Internet]. Horizon 2020. 2013. [Cited 2015 April 15]. Available from http://ec.europa.eu/ programmes/horizon2020/en/h2020-section/public-engagementresponsible-research-and-innovation

28. Fox F. The surest way to let the animal rights extremists win, warns Fiona Fox, is for scientists to hide away and refuse to argue their case. New Sci. 2005;187:22.

29. Caulfield T, McGuire A. Athletes' use of unproven stem cell therapies: adding to inappropriate media hype. Mol Ther. 2012;20: 1656-8.

30. Yamaner M, National Science Foundation, National Center for Science and Engineering Statistics. Federal funding for research drops by $9 \%$ in FY 2011 [Internet]. 2013. [Cited 2015 April 15]. Available from: http://www.nsf.gov/statistics/infbrief/nsf13336/

31. O'Brien TL, Noy S. Traditional, modern, and post-secular perspectives on science and religion in the United States. Am Sociol Rev. 2015;80:92-115.

32. Ostergren JE, Dingel MJ, McCormick JB, et al. Unwarranted optimism in media portrayals of genetic research on addiction overshadows critical ethical and social concerns. Journal of Health Communication: International Perspectives. 2015;20:555-65.

33. Kamenova K, Caulfield T. Stem cell hype: media portrayal of therapy translation. Sci Transl Med. 2015;7:1-4.

34. Lau D, Ogbogu U, Taylor B, et al. Stem cell clinics online: the direct-to-consumer portrayal of stem cell medicine. Cell Stem Cell. 2008;3:591-4.

35. Regenberg AC, Hutchinson LA, Schanker B, et al. Medicine on the fringe: stem cell-based interventions in advance of evidence. Stem Cells. 2009;27:2312-9.

36. Ogbogu Y, Rachul C, Caulfield T. Reassessing direct-to-consumer portrayals of unproven stem cell therapies: is it getting better? Regen Med. 2013;8:361-9.

37. Ryan KA, Sanders AN, Wang DD, et al. Tracking the rise of stem cell tourism. Regen Med. 2010;5:27-33.

38. Dlouhy BJ, Olatilewa A, Rao RC, et al. Autograft-derived spinal cord mass following olfactory mucosal cell transplantation in a spinal cord injury patient. J Neurosurg Spine. 2014;21:618-22.

39. Jabr F. In the flesh: the embedded dangers of untested stem cell cosmetics [Internet]. Scientific American. 2012 [Cited 2015 April 15]. Available from: http://www.scientificamerican.com/article/ stem-cell-cosmetics/

40. International Society for Stem Cell Research. A closer look at stem cell treatments [Internet]. 2010 [Cited 2015 April 15]. Available from: http://www.closerlookatstemcells.org/

41. Murdoch CE, Scott CT. Stem cell tourism and the power of hope. AJOB. 2010;10:16-23.

42. Scott CT. The case for stem cell counselors. Stem Cell Rep. 2014;4: $1-6$. The author describes and argues for the creation of a new 
counseling profession, akin to genetic counseling, to support patients interested in stem cell trials and unproven treatments.

43. Thomas B. A disease of scienceyness [Internet]. Medium. 2015

[Cited 2015 April 15]. Available from: https://medium.com/@ writingben/a-disease-of-scienceyness-7b5571a34953
44. Regenberg AC. Stem cell science should be tweeted. Regen Med. 2014;9:125-7.

45. Ronson J. So you've been publicly shamed. London: Picador; 2015. 